\title{
INFLUÊNCIA DO DIREITO FRANCÊS SOBRE O DIREITO BRASILEIRO*
}

\author{
Antonio Junqueira de Azevedo \\ Professor Titular do Departamento de Direito Civil \\ Ex-Diretor da Faculdade de Direito da USP
}

Uma exposição sobre as influências do direito francês sobre direito brasileiro exige previamente uma explicação histórica. Dividiremos, portanto, nossa conferência em duas partes: uma, genérica, que tomará o direito brasileiro em suas origens, ainda ligado ao direito português, e prolongando-se após a Independência (1822) até a proclamação da República (1889); e outra, específica, a partir da República e relativa aos vários ramos do Direito (Direito Civil, Comercial, Constitucional, Administrativo, Penal, etc.), com temas delimitados. No fundo, a divisão da exposição obedece a duplo critério, o que pode não ser muito lógico mas nos parece adequado ao objeto: a primeira parte é cronologicamente anterior e, nela, o direito será estudado quanto às suas fontes e quanto à doutrina; a segunda, é mais recente e o direito será tomado fracionariamente, em seus vários campos.

\section{Primeira Parte - Apanhado Histórico}

Foi justamente no século XVI, no esplendor da civilização portuguesa, que se deu a primeira grande influência do direito francês sobre direito português. $\mathrm{O}$ reino de Portugal parece ter sido o primeiro a se consolidar na Europa; já no século XII, com o rei Afonso Henrique (1128-1185), Portugal tinha aproximadamente seu atual território, além de estrutura administrativa própria; tinha língua nacional e estava reconhecido como reino independente, quer pelo rei de Castela (Afonso VII, em 1144) quer pelo Papa (Alexandre III, em 1179, Bula Manifestis probatum). A precocidade de Portugal como estado-nação se revelou vantajosa, historicamente; Portugal pôde se projetar no concerto das nações, graças aos feitos realizados nos séculos XIV e XV com as grandes navegações e

* Conferência proferida em Paris, em 26 de novembro de 1993, a convite da Universidade de Paris II. 
descobrimentos: ilhas Canárias (certamente ainda no século XIV), Madeira e Açores (ocupadas na primeira metade do século XV), Cabo Bojador (1434, por Gil Eanes), passagem do Cabo da Boa-Esperança (ex das Tormentas, 1487, por Bartolomeu Dias) e, finalmente, a chegada à Índia com Vasco da Gama, em 1498. Em 22 de abril de 1500, o Brasil é oficialmente descoberto por Pedro Álvares Cabral, a caminho das Índias. No começo do século XVI, Portugal está, pois, no seu apogeu, tanto no campo das artes quanto no econômico. Juridicamente, Portugal, nessa época, tem também alguma precocidade; em 1447, sendo rei Afonso V (mas ainda regente o infante D. Pedro) é aprovada a reunião, em um só corpo, de todas as leis do reino; isto foi feito em cinco livros que tomaram o nome de Ordenações Afonsinas. Os Livros I e II tratavam das relações entre os órgãos de governo e entre o clero, a nobreza e o povo; o Livro III dispunha, do processo judicial; o Livro IV, de direito privado; e o Livro V, de direito penal. Pouco tempo depois, o Rei D. Manoel, chamado justamente de $O$ Venturoso, manda refazer e atualizar este corpo de leis; isto foi realizado exatamente como, depois, se fariam os códigos modernos, ou seja, de forma unitária, sem referência a leis anteriores, inovando, e com redação simplificada, em estilo que podemos considerar moderno. São as Ordenações Manuelinas, publicadas definitivamente em 1521 (houve edição anterior, de 1514, mandada recolher, sob pena de multa e degredo, para evitar confusão entre os dois textos). As Ordenações Manuelinas têm a mesma distribuição das matérias que as Afonsinas, isto é, cinco livros: os dois primeiros, de direito público; o terceiro, muito completo, de direito processual; o quarto, de direito privado; e o quinto, de direito penal.

A grande influência do direito francês foi, então, a do humanismo jurídico (Budé, Cujas, Alciato, Doneau, Mudée), com suas preocupações de depuração dos textos do Corpus Juris Civilis, liberando-os do excesso de comentários, com sua atividade de crítica histórica, estabelecendo o significado original das regras jurídicas romanas, e com seu zelo pelo estilo. As leis portuguesas eram, então, muito aprimoradas especialmente em matéria de direito público mas, quanto ao direito privado, o Livro Quarto das Ordenações Manuelinas, apesar de claro, na verdade, trazia somente disposições sobre questões específicas; no fundo, a maior parte das questões de direito privado continuavam sendo resolvidas com fundamento no Corpus Juris Civilis, especialmente no Digesto. Segue-se daí que o ensino do direito privado se fazia com base no Direito 
Romano, tal e qual apresentado pela glosa de Acursio e acompanhado dos comentários dos pós-glosadores, especialmente de Bartolo. Por influência francesa, surge, então, a corrente dita "escola culta" que reage contra os modelos metodológicos dos comentadores; dela fazem parte Antonio de Gouveia (Antoine ou Antonius Gouveanus, m. 1556) que foi estudante em Paris em 1527 e, depois, professor de humanidades em Bordeaux, Toulouse, Avignon, Lyon e Paris, e defendia a "união do estudo do direito com as letras humanas"; também Luiz Teixeira, Manuel da Costa e Diogo de Sá.

O conservadorismo dos juristas portugueses, porém, jamais permitiu que o espirito crítico do humanismo jurídico francês fosse levado às suas últimas conseqüências; não se admitiu, em Portugal, que os textos do próprio Corpus Juris pudessem ser colocados em dúvida através, por exemplo, do estudo da interpolações. A apologia da livre investigação sobre o direito (o libere philosophari) ficou somente na liberação dos textos romanos de seus comentários de glosadores e pós-glosadores; isto está claro na reforma da Universidade feita por D. João III, sucessor de D. Manoel, já em 1539 (Regimento da Instituta) quando se desaconselha formalmente a citação exaustiva de opiniões e se prescreve que as soluções para os casos devem ser buscadas diretamente nos textos legais. ${ }^{2} \mathrm{De}$ qualquer forma, então, por influência francesa, em matéria de direito privado, os doutrinadores são substituidos pelas leis. Nos séculos seguintes, XVII e XVIII, em Portugal, as leis, por sua vez, perderão importância diante da jurisprudência.

Todavia, parece mais conveniente, nesta altura da exposição, deixarmos de lado tudo que possa ter ocorrido em Portugal e passarmos a falar exclusivamente da situação do direito no Brasil e, embora não seja propriamente influência do direito francês sobre o direito brasileiro, vale a pena lembrar que, no mesmo século XVI, desde 1504, intensificando-se no reinado de Francisco I (15151547) e continuando no reinado de Henrique II (1547-1559), os franceses, através de corsários, mais ou menos protegidos pelo seu Rei, estiveram frequentemente nas costas brasileiras. Daí, duas importantes conseqüências nas nossas estruturas administrativas: a primeira, em 1534, quando o rei de Portugal, D. João III (1521-

1 Ver Antonio Manoel Hespanha, História das Instituições, Coimbra, Livraria Almedina, 1982, p. 505; Nuno Espinosa Gomes da Silva, História do Direito Português, $2^{2}$ ed., Lisboa, Fundação Calouste Gulbenkian; idem, Humanismo e Direito em Portugal no Século XVI, Lisboa, 1964.

2 . Ver obras citadas na nota anterior. 
1558) para melhor defender a colônia, após várias trocas de cartas e tratados com $o$ rei da França (Fontainebleau, 1531 e Baione, 1536), estabeleceu o sistema das capitanias hereditárias (15 capitanias) e a segunda, quando Estácio de Sá, sobrinho do Governador Geral do Brasil, Mem de Sá, após a expulsão dos franceses trazidos por Villegagnon (Nicolas Durand de Villegagnon que estava sob os auspícios do almirante Gaspard de Coligny) ordenou a fundação, na Baia da Guanabara, da cidade do Rio de Janeiro (1565). ${ }^{3}$

A chegada das caravelas portuguesas no território que viria a ser o Brasil e a colocação dos marcos de pedra, que representavam a tomada de posse da nova terra, têm a curiosa conseqüência de que também as leis portuguesas, como quê ao lado dos marinheiros, desembarcaram nas praias brasileiras e estenderam sua incidência; depois, à medida que os exploradores, especialmente os bandeirantes, adentravam pelas matas, conhecendo novos rios, ocupando florestas e campos, as mesmas leis portuguesas os acompanhavam, como uma sombra. Há nessa matéria, embora isto escape ao nosso tema, conseqüências interessantíssimas: nas chamadas sesmarias, por exemplo, de que resultaram os latifúndios (= grandes fazendas) brasileiros, o mesmo texto legal português vê suas intenções alteradas em 180 graus. Nas Ordenações Manuelinas, havia regra que hoje diriamos "altamente progressista" no sentido de que as terras não cultivadas por seus proprietários, isto é, terras estéreis, deveriam ser distribuídas pelas autoridades para quem nelas pudesse plantar. A exigência para a distribuição era esta: poder aproveitar as terras distribuídas. Ora, essa regra, em Portugal, beneficiava aos agricultores nãoproprietários, os "sem terra" contra os proprietários desleixados. No Brasil, porém, todas as terras estavam sem cultivo e, assim, todas podiam ser distribuidas; era preciso, porém, para as receber, ter os meios para o seu aproveitamento. Ora, as terras eram tantas que somente podiam ser distribuidas a quem tinha muito capital, eis que, para desbravar grandes áreas cobertas por florestas e enfrentar índios, os pretendentes ao recebimento das sesmarias tinham que provar ter meios, isto é, ter escravos, dinheiro, instrumentos agrícolas, armas. Segue-se daí que a mesma regra

3 Waldemar Ferreira, História do Direito Brasileiro, São Paulo, Max Limonad, 1955, t. 3, p. 301. No século XVII, os franceses estabeleceram-se novamente no Brasil, desta vez, no Maranhão. 
que, em Portugal, tinha alto alcance social, passou, no Brasil, a favorecer os ricos e a formação de latifúndios. ${ }^{4}$

A partir de 1580, Portugal, já em decadência, esteve unido à Espanha, sob os Felipes (Felipe II, III e IV). ${ }^{5}$ Em 1649, deu-se a restauração da monarquia lusitana, assumindo o trono de Portugal D. João IV, o primeiro da dinastia dos Bragança, mas, nem por isso, pode-se dizer que, no decorrer dos séculos XVII e XVIII, tenha sido estancado o processo de decadência da civilização portuguesa. No Brasil, deu-se o inverso; houve desenvolvimento populacional e progresso econômico; no século XVIII, com a descoberta das minas de ouro, o Brasil progrediu muito, podendo-se afirmar que, ao final do século, a economia brasileira tornou-se superior à portuguesa. Esta situação, infelizmente, não encontrava correspondência do ponto de vista cultural, eis que não havia no Brasil universidade ou escola superior. ${ }^{6}$

Data dessa época, fins do século XVIII, a primeira grande influência cultural francesa no Brasil. Embora juridicamente de nacionalidade portuguesa, os brasileiros, de fato, já então, se distinguiam dos originários da Metrópole; tinham, em graus diferentes, sangue índio ou negro; eram, pois, em geral, mais morenos, quando não, declaradamente mestiços. Além disso, falavam um português mais lento, com vocabulário nem sempre idêntico. Viam o governo como algo a eles estranho, mesmo porque a vida cotidiana no Brasil se fazia com muita autonomia; por força da geografia e da extensão territorial, o governo tinha pouca participação nas atividades diárias da população. As idéias de Jean-Jacques Rousseau e dos enciclopedistas tiveram, então, voga entre os poucos intelectuais brasileiros. Em 1789, foram presos pelo Governo Português os chamados "inconfidentes" de Minas Gerais, que pretendiam a independência do Brasil. Seu representante mais famoso, Tiradentes, terminou enforcado e é o herói nacional do Brasil (na verdade, não era propriamente um líder do movimento porque se tratava de pessoa simples, era

4 Cf. nossa conferência, na Universidade de Roma, La Sapienza, em 2 de fevereiro de 1992, sobre a formação da propriedade rural no Brasil.

5. No reinado dos Felipes, Portugal conservou sua autonomia administrativa. As Ordenações Manuelinas foram substituidas pelas Ordenações Filipinas (1604), que foram obras de portugueses e não de espanhóis.

6. Havia na estrutura judicial, portuguesa, nesta ocasião, um tribunal superior, em Lisboa, denominado Casa da Suplicação, equivalente ao Tribunal de Cassação; abaixo dele, cinco tribunais de segunda instância: no Porto, Evora, Goa (Índia), Rio de Janeiro e Bahia (três, portanto, localizados fora de Portugal, sendo dois, no Brasil). 
alferes, mas revelou-se realmente decidido a fazer a independência e assim se proclamou durante os depoimentos no processo, sendo o único punido com a morte). É interessante observar que, desde então, e durante aproximadamente duzentos anos, foi a cultura francesa a principal fonte estrangeira de nossa formação intelectual (somente no século atual, em torno da década de 60 , é que este papel foi tomado pela cultura americana, que, hoje, predomina largamente). Até mesmo o pouco que os inconfidentes sabiam da recente Constituição Americana era através de tradução francesa. Muitas vezes, os autores seguidos não eram os de primeira linha; por exemplo, eram muito lidas, conforme se vê pelos autos da devassa, nos termos de sequestro dos bens dos revoltosos, as obras do Abade Reynal.

O advento do Império Napoleônico, logo depois, teve consequiências diretas no "status" jurídico do Brasil; como se sabe, o Imperador dos franceses, por causa do Bloqueio Continental, mandou o general Junot, em 1807, invadir Portugal e depor a Casa de Bragança; nessa ocasião, a Corte portuguesa pôs em execução um velho plano que já havia sido pensado em outra ocasião (quando a ameaça para os Braganças era a Espanha). Praticamente toda a elite portuguesa, cerca de dez mil pessoas aproximadamente (a rainha D. Maria I, a louca, e o príncipe regente, futuro D. João VI, o alto clero, os ministros, os juizes de tribunais superiores, os nobres, os comerciantes ricos, os quadros superiores da administração, e até mesmo a criadagem do Paço) partiu para o Brasil, estabelecendo-se no Rio de Janeiro; trata-se de caso único na História. A partir daí, o Rio de Janeiro, cidade americana, passou a ser a capital de um reino europeu; mesmo após a queda de Napoleão e a libertação de Portugal, esta situação continuou, perdurando até 1821. Além disso, depois da Independência brasileira (1822) e durante mais 67 anos, isto é, até a proclamação da República, uma família dinástica européia reinou em terras do Novo Mundo.

Outra consequiência, foi que, precisamente em 1808, os brasileiros tomaram uma parte do território francês! Quer dizer, tomamos a Guiana Francesa, incorporando-a ao nosso território. Isto fez com que a França, no Congresso de Viena, em 1815, juntamente com a Espanha, exigisse que um representante brasileiro, além do próprio representante de Portugal, assinasse o Tratado de Viena. Os governos europeus se antecipavam, assim, a qualquer proclamação de independência do Brasil; reconheciam, na verdade, a situação de fato de autonomia 
do Brasil. Diante disso, em fins do mesmo ano de 1815, o rei de Portugal elevou o Brasil à categoria de reino, denominando-o, por Carta de Lei (16 de dezembro de 1815), Reino Unido ao de Portugal.' Esta data, porém, não é considerada no Brasil como a da independência, porque, nessa ocasião, pouca mudança houve, eis que a Corte continuava no Rio de Janeiro. A independência brasileira somente viria alguns anos depois, em 1822, quando os portugueses exigiram a volta do rei para Lisboa; de resto, a Independência resultou de uma espécie de composição entre nacionalistas brasileiros conservadores e o príncipe herdeiro português, D. Pedro I; o Brasil separou-se de Portugal mas a Casa reinante continuou (permanecendo até a proclamação da República, em 1889).

A partir de 1804, como se sabe, é quase universal a influência do Código Civil francês. No Brasil, as leis portuguesas continuaram a vigorar após a Independência. A Constituição outorgada em 1824 previa a feitura de códigos (civil e penal, art. 179, n. 18). Em 1827, foram instalados os cursos jurídicos de São Paulo e Olinda. Entretanto, apesar da muita leitura de autores franceses pelos professores e apesar da determinação constitucional, tivemos grandes dificuldades para a elaboração do Código Civil; as razões das dificuldades não estavam na falta de juristas que o fizessem, porque, na verdade, durante todo o periodo imperial brasileiro, vários projetos foram elaborados, especialmente o famoso Esboço, de Teixeira de Freitas, que foi servir como base para o Código Civil argentino (o projeto argentino foi de Velez-Sarsfield com fundamento declarado nos trabalhos de Teixeira de Freitas). As razões, a meu ver, estavam em que o grande jurista citado, encarregado do primeiro projeto, não concordava com a distribuição das matérias no Código Civil francês; anteriormente (1858), já havia elaborado uma Consolidação das Leis Civis com uma Parte Geral - tal e qual, mais tarde, teria o BGB -, e, depois, elaborou um projeto, o Esboço, realmente inovador, precursor de tempos futuros, que tinha a Parte Geral, baseava-se na distinção entre direitos reais e pessoais e unificava direito civil e direito comercial. Esse projeto foi recusado pelo

7. O preâmbulo da Carta de Lei diz: '... e outrossim reconhecendo quanto seja vantajosa aos meus fiéis vassalos em geral uma perfeita união e identidade entre os meus Reinos de Portugal e dos Algarves, e os meus dominios do Brasil, erigindo esses àquela graduação e categoria politica e pelos sobreditos predicados lhes deve competir, e na qual os ditos meus dominios já foram considerados plenipotenciários das potências que formaram o Congresso de Viena, assino o Tratado de Aliança concluido aos 8 de abril do corrente ano, como no tratado final do mesmo Congresso. Sou portanto servido e me apraz ordenar o seguinte: I - Que desde a publicação desta Carta de Lei o Estado do Brasil seja elevado à dignidade, preeminência e denominação de - Reino do Brasil -;... 
Ministro da Justiça, José de Alencar, personalidade conservadora (à moda dos intelectuais franceses românticos do seu tempo, Chateaubriand, Lamartine, Victor Hugo, José de Alencar foi também grande romancista). Outra razão das dificuldades do Código Civil, e existente também para os projetos posteriores, era tipicamente brasileira: a escravidão. A produção agrícola (cana-de-açúcar, café, etc.), os trabalhos domésticos e o vulto do capital empregado no tráfego de escravos impediam a abolição da escravidão mas, ao mesmo tempo, os juristas brasileiros não queriam elaborar um Código Civil que aparecesse aos olhos do Mundo como consagrando essa iniquidade. A consequiência foi que, durante todo o Império, não tivemos o Código Civil (a abolição da escravidão se deu em 1888 e, em 1889, foi proclamada a República).

Por sua vez, o Código Penal (1830), o Código de Processo Penal (1832, de concepção muito liberal e alterado em 1842) e o Código Comercial (1850) não tiveram direta influência de seus congêneres franceses; foram, antes, fundamentados na legislação portuguesa.

De todo o exposto, quanto a esta Primeira Parte, podemos sintetizar dizendo que: $1^{\circ}$ ) a França, quer diretamente, através de ações concretas, quer indiretamente, através de seus intelectuais, teve enorme influência no Direito brasileiro, isto é, no direito-norma e no direito-doutrina; alterou estruturas administrativas, levando até mesmo à mudança do status jurídico do país, movimentou intelectuais, formou professores; $2^{\circ}$ ) 0 direito francês, entretanto, até a República, não teve influência notável; nenhum de nossos Códigos nem a legislação civil de então foi copiada ou adaptada de legislação francesa.

\section{Segunda Parte - Direito Atual}

O direito brasileiro posterior à República, ou seja, praticamente o direito brasileiro do século $\mathrm{XX}$, tem a seguinte característica: conforme o ramo do direito, varia o país que o influencia. No direito processual e no direito penal, predomina a Itália; no direito administrativo e no direito internacional, a França; no direito comercial, os Estados Unidos; no direito civil, França, Alemanha e Portugal disputam a primazia; no direito constitucional, finalmente, campo que atualmente preocupa o jurista brasileiro, as soluções francesas são muito citadas, especialmente quanto à forma de governo, mas, sendo aí muitos os problemas, 
também as Constituições dos demais países são consultadas. Pode-se dizer, pois, paradoxalmente, que a originalidade do atual direito brasileiro está em saber copiar.

Para não nos estendermos demais, vejamos somente a influência francesa que, como foi dito, é muito forte no direito administrativo, no direito internacional e no campo de nossa especialidade, o direito civil, em alguns de seus temas.

$\mathrm{O}$ direito administrativo brasileiro, que vem sendo ensinado no curso jurídico desde 1854, é inteiramente tributário do direito francês. É verdade que não temos tribunais administrativos decidindo em última instância, como o Conceil d'État; existe a determinação constitucional de que "a lei não excluirá da apreciação do Poder Judiciário lesão ou ameaça a direito" (Constituição da República, art. $5^{\circ} \mathrm{XXXV}$ ) e um tribunal administrativo, para nós, não faz parte do Poder Judiciário. Entretanto, toda a discussão sobre o serviço público, entre a chamada Escola do Serviço Público, ou de Bordeaux, tendo por chefe Leon Duguit, e a corrente contrária de Maurice Hauriou teve grande repercussão no Brasil. São também muito citados os nomes de Gaston Jèze, Henri Berthélemy, Roger Bonnard e outros mais recentes, Laubadère, Jean Waline, Georges Vedel, Paul Gaudemet, para não falarmos nos nomes de hoje e na Revue Française de Droit Administratif.

No direito internacional, quer público, quer privado, a influência dos autores franceses sobre os brasileiros é total; além das decisões da Corte de Haia e de tratados internacionais, até mesmo escritores alemães são conhecidos através de versões francesas. Henri Batifol foi, durante anos, a referência constante. Por conveniência, omitimos os nomes mais recentes.

No direito civil, pode-se dizer que, a partir da entrada em vigor do Código Civil, em $1^{\circ}$ de janeiro de 1917 , o direito brasileiro tomou um novo numo. Do direito francês, herdou a dicotomia: Código Civil e Código Comercial; não seguimos a idéia de unificação do direito privado de Teixeira de Freitas (concretizada na Itália, em 1942). O Código Civil brasileiro, porém, se diferencia completamente do sistema do Código de Napoleão; ele tem a mesma divisão do Burgerlich Gesetzbuch de 1896, com uma parte geral e uma parte especial. A Parte Geral segue com exatidão as lições da Pandectista; ela tem um livro para as pessoas, outro para os bens e um terceiro, para o ato jurídico (terminologia francesa mas, no fundo, o ato jurídico, do Código Civil, é o Rechtsgeschäft dos alemães). A 
Parte Especial tem quatro livros: Direito de Familia, Direitos Reais, Direito das Obrigações e Direito das Sucessões (exatamente como o Código Civil alemão).

Sobre o ato jurídico, nós seguimos a teoria pandectista do Rechtsgeschäft e a teoria anti-causalista de Planiol; já a teoria das nulidades do ato jurídico no Direito Brasileiro acompanha a doutrina francesa, a tal ponto que Rene David aconselha a quem pretenda estudá-la ler a obra do jurista francês Solon, escrita em 1835 e publicada em tradução brasileira em revista especializada.

A concepção do erro como defeito do ato jurídico (art. 96 do Código Civil brasileiro) é a mesma do art. 1.169 do Código Civil francês e nossos civilistas seguem seus colegas franceses em tudo que diz respeito a vícios do consentimento.

$O$ direito brasileiro se separa radicalmente do direito francês, mas também do direito alemão, no que se refere ao sistema de aquisição da propriedade imóvel. Para o Código de Napoleão, como se sabe, o contrato tem o efeito de transmitir a propriedade. No direito brasileiro, a propriedade não se adquire solo consensu; ele não adotou integralmente o sistema alemão, centrado num "acordo formal de transmissão" que se coloca como "convenção que tem efeito real" a inscrição no registro imobiliário assumindo o caráter de ato jurídico abstrato, isto é, este ato registrado nos livros fundiários, segundo o $\mathrm{BGB}$, se separa do ato jurídico contratual subjacente. Assim, ao contrário do direito francês em que o ato entre as partes produz todos os efeitos translativos, no direito alemão, é o registro do "acordo de transmissão" que produz um efeito probatório absoluto, em presunção juris et de jure. Para o Código Civil brasileiro, diferentemente do Código de Napoleão e do BGB, a transmissão da propriedade imobiliária não se faz solo consensu, e não tem, também, acordo de transmissão separado do contrato; somos mais fiéis à concepção do Direito Romano, segundo o qual a propriedade das coisas não se transfere pelo contrato ("traditionibus et usucapionibus non nudis pactis, dominia rerum transferuntur") exigindo um ato material e concreto que, para os bens móveis é a tradição e para os bens imóveis, a inscrição do contrato no registro. No Brasil, como na antiga Roma, é preciso, para aquisição dos bens, como diziam os juristas da Idade Média, titulus ("o contrato") plus modus (a tradição para os móveis e o registro de contrato para os imóveis). (Ver sobre aquisição de bens imóveis, no Direito Francês, Mazeaud, Leçons de Droit Civil, v. 2 n. 1.612; Planiol, Ripert e Boulanger, Traité Elémentaire, v. 1, n. 2.885; Aubry e Rau, Cours, v. 2 parágrafo 207; Marty e Raynaud, Droit Civil, v. 2, n. 53; sobre a 
aquisição da propriedade imobiliária no direito alemão, Eneccerus, Kipp y Wolff, Tratato, Derecho de Cosas, v. 1, parágrafo 26 e seguintes; Hedemann, Derechos Reales, parágrafo 9; sobre aquisição da propriedade imobiliária no direito brasileiro, Soriano Neto, Publicidade Material e Registro Imobiliário, n. 59; Serpa Lopes, Curso de Direito Civil, v. 6, n. 338; Clóvis Bevilaqua, Direito das Coisas, v. 1, p. 147; Caio Mario da Silva Pereira, Instituiçzes do Direito Civil, v. 4, n. 303; Orlando Gomes, Direitos Reais, cap. XIII, e também, nossa conferência na Universidade de Roma, La Sapienza, em 5 de fevereiro de 1992).

Todavia, em outros domínios civilistas, há presença do direito francês. A teoria da responsabilidade civil no Código Civil brasileiro é totalmente derivada do Código de Napoleão, cujo art. 1.382 determina: "Todo fato causado pelo homem, que causa prejuizo a outrem, obriga aquele por cuja culpa este aconteceu, a reparar o dano." E o art. 1.383 estabelece: "Todo homem é responsável pelo prejuizo que causou, não somente por seu fato mas também por sua negligência e imprudência." $\mathrm{O}$ art. 159 do Código Civil brasileiro dispõe: "Aquele que, por ação ou omissão voluntária, negligência, ou imprudência, violar direito, ou causar prejuizo a outrem, fica obrigado a reparar o dano. A verificação da culpa e a avaliação da responsabilidade, regulam-se pelo disposto neste Código." A teoria brasileira da responsabilidade parte daí e seu desenvolvimento sobre a responsabilidade por fato de terceiro ou por fato das coisas acompanha direito francês.

É igualmente importante observar que a evolução da responsabilidade no direito francês, a partir de Josserand (De la Responsabilité des Choses Inanimées, Paris, 1897; Cours de Droit Civil Positif Français, v. 2, n. 486) e Gaston Morin (La Révolte du Droit contre le Code, p. 62) levou os professores brasileiros à doutrina da responsabilidade objetiva, que tem entre nós defensores importantes (Alvino Lima; José de Aguiar Dias; Wilson Melo da Silva e os diversos projetos de um novo Código Civil). Hoje, dessa matéria, procuramos também soluções do direito francês para os problemas dos direitos dos consumidores, apesar da existência de um Código de Defesa do Consumidor muito atual.

No Direito de Família, o princípio da irrevogabilidade do regime de bens no casamento está presente nos arts. 230 do Código Civil brasileiro e 1.396 do Código Civil francês. Embora adotando a doutrina romana de filiação legítima pater is est quem nuptias demonstrant - encontramos nos dois códigos, o francês 
(art. 312) e o brasileiro (art. 340), a mesma exceção quando intervém a impossibilidade física da coabitação. Mas é preciso dizer que, hoje, todo Direito de Família está alterado no Brasil; a nova Constituição (de 1988) fixou princípios em contradição com o Código Civil e temos muitos problemas de compatibilização.

Numerosos pontos podiam ainda ser indicados no Código Civil brasileiro como copiados do Código Civil francês, lembrando, a título de exemplo, a instituição da repetição do indébito, o conceito de perdas e danos e as formas testamentárias, mas seria cansar demais os ouvintes ou leitores. Esperamos, porém, ter dado uma idéia deste vasto assunto. 